\title{
PAT'TERNS OF WOLF PACK MOVEMENTS PRIOR TO KILLS AS READ FROM TRACKS IN ALGONQUIN PROVINCIAL PARK, ONT., CANADA
}

\author{
by \\ JAN HILCO FRIJLINK \\ Department of Animal Bebaviour, University of Amsterdam, The Netherlands
}

\begin{abstract}
From data, gathered by the author and his students, during a wolf study in Algonquin Provincial Park, Canada, six kills of white-tailed deer by wolf packs are described. Case histories are reconstructed by means of interpreting tracks. In one case a wolf was also killed, this animal turned out to have been suffering from rabies.
\end{abstract}

\section{INTRODUCTION}

Algonquin Provincial Park is an area of about $7,500 \mathrm{~km}^{2}$ on the watershed of the Ottawa River and Lake Ontario drainage systems. The vegetation consists mainly of mixed hardwood forest, dotted with thousands of lakes, together some $8 \%$ of the total surface. One highway (no. 60) runs through the southeastern part of the park, in addition there are numerous dirt roads, logging roads and some abandoned railroad tracks. Because of the activities of lumbering companies the forest is relatively young - in general between 20 and 50 years with lush undergrowth, which provides the herbivores of the park with large amounts of browse (Lambert \& Pross, 1967).

At the time of this research, the park was inhabited by some 300 wolves (Canis lupus), who preyed for more than $95 \%$ on the 30,000 whitetailed deer (Odocoileus virginianus) of the park (Pimlott et al., 1969). Both during the winter 1968-1969 and 1969-1970 I spent about 55 days in the Park, usually accompanied by 5 to 10 of my students. Our major aim was to study the behaviour of the wolf under natural conditions, especially cooperative hunting techniques. Because of the extreme shyness of the wolf, however, direct observation was not possible, so we had to rely on tracking. Reading tracks in order to reconstruct the behaviour is risky in many respects. One can be easily misled in the interpretation of purely coincidental track patterns, the time sequence is of ten very hard to find out or even completely impossible, snow conditions may be such, that no clear tracks are left or tracks may be completely obliterated. Nevertheless, in some cases tracks were clear enough to allow for a tentative interpretation of the movements of both prey and predators just prior to the kill. In this paper a description of these case histories is presented.

I agree with Mech (1970) as to the desirability of more direct information on wolf hunting techniques, but, since very few is available, especially in forested areas, I hope publication of my data is justified, inasmuch as it is intended to be a contribution to the little that is known about wolf hunting techniques (e.g. Murie, 1944; Crisler, 1956; Mech, 1966; Rutter \& Pimlott, 1968).

\section{TRACK PATTERNS OF SIX KILLS}

Tracking was carried out by means of following wolves on snowshoes in the so-called research area of Algonquin Park (fig. 1). Wolf packs followed had received the following names: Potter, Fool's, Madawaska and Source packs. Groups of followers consisted usually of between 2 and 5 people, daily hikes covered on the average 15 to $25 \mathrm{kms}$, occa- 


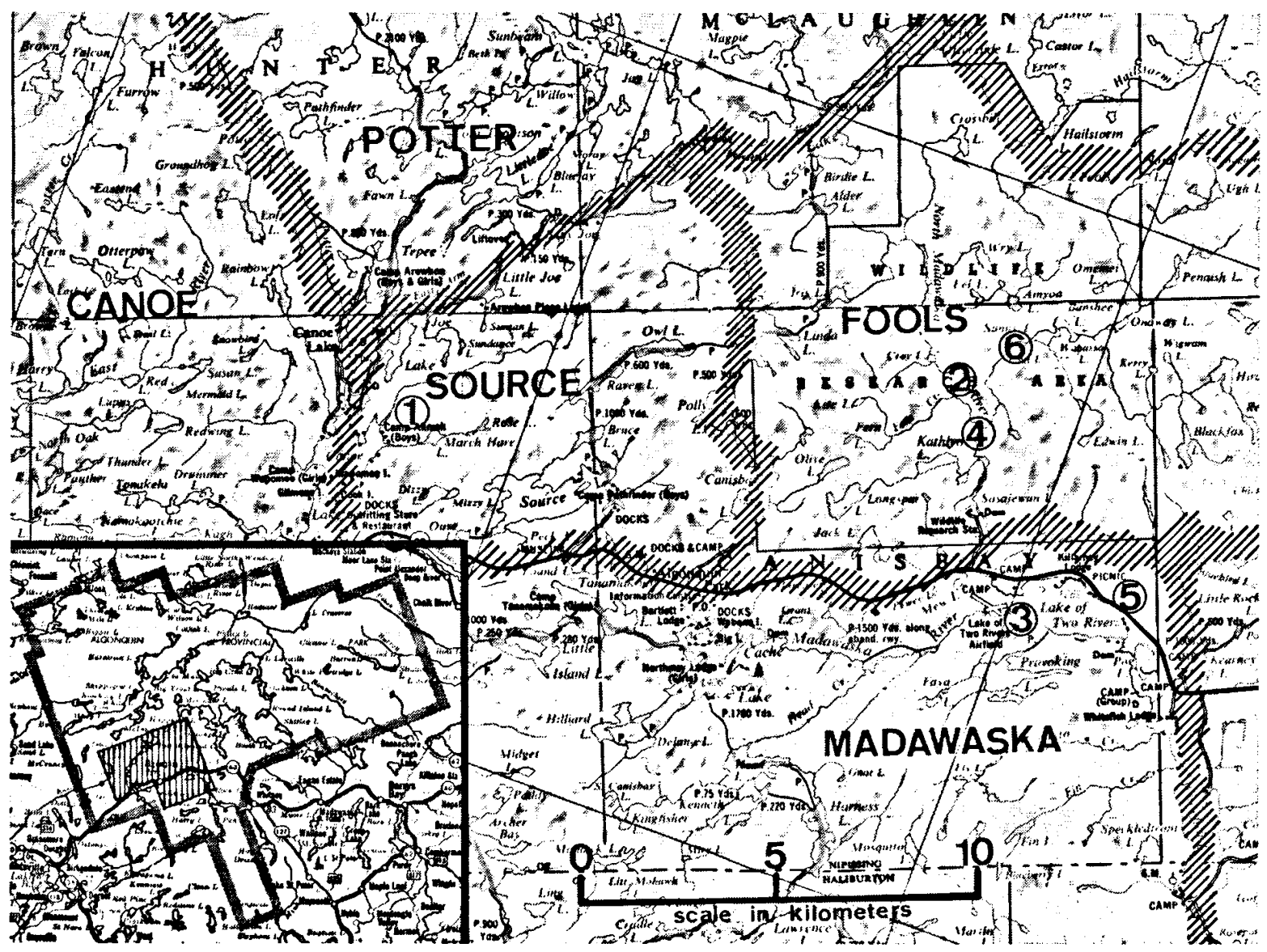

Fig. 1. Research area Algonquin Park (Canada)

sionally more. All traces left by a travelling pack would be worked out as much as possible. Quite often a travelling pack would fan out, especially while traversing a frozen lake or clearing in the forest, or split up in twos and threes and afterwards come together again especially where vegetation made the going difficult or on well established routes, the so-called "wolf highways" (fig. 2).

Occasionally the remainder of a deer was found, while we followed wolf tracks. In such a case tracks in the vicinity were carefully studied in order to draw up a picture as detailed as possible about the movements of wolves and prey prior to the kill. Usually a kill was announced well in advance because of flocks of ravens circling above the kill site.

In five such cases a more or less complete record of what happened could be read from the tracks.
A description of these kills is given below. Finally a sixth case is added, although the tracks found did not permit anything even approaching a reliable reconstruction, but because in this case the death of a wolf was caused by its prey, a white-tailed deer buck. To my knowledge such an accident has never been reported in the literature, therefore I decided to include this case in spite of the rather frustrating lack of data.

a) Arowhon Taylor Statten Road kill

(nr. 1 in fig. 1, fig. 6)

Found on Febr. 1, 1969; kill (fawn) made by Source Pack, consisting of an estimated number of 5 wolves.

One or two wolves had chased an adult deer and a fawn down the snowploughed road. One of the deer had been bleeding slightly as could be seen from droplets of blood in the hardpacked snow on the road. Because of the ploughing, tracks were only barely visible. Three wolves then came bounding out of the forest, brought down and killed the fawn. The adult deer (the mother?) made a good escape into the forest on the opposite side of the road. The wolves started eating on the road, then dragged their prey off, 


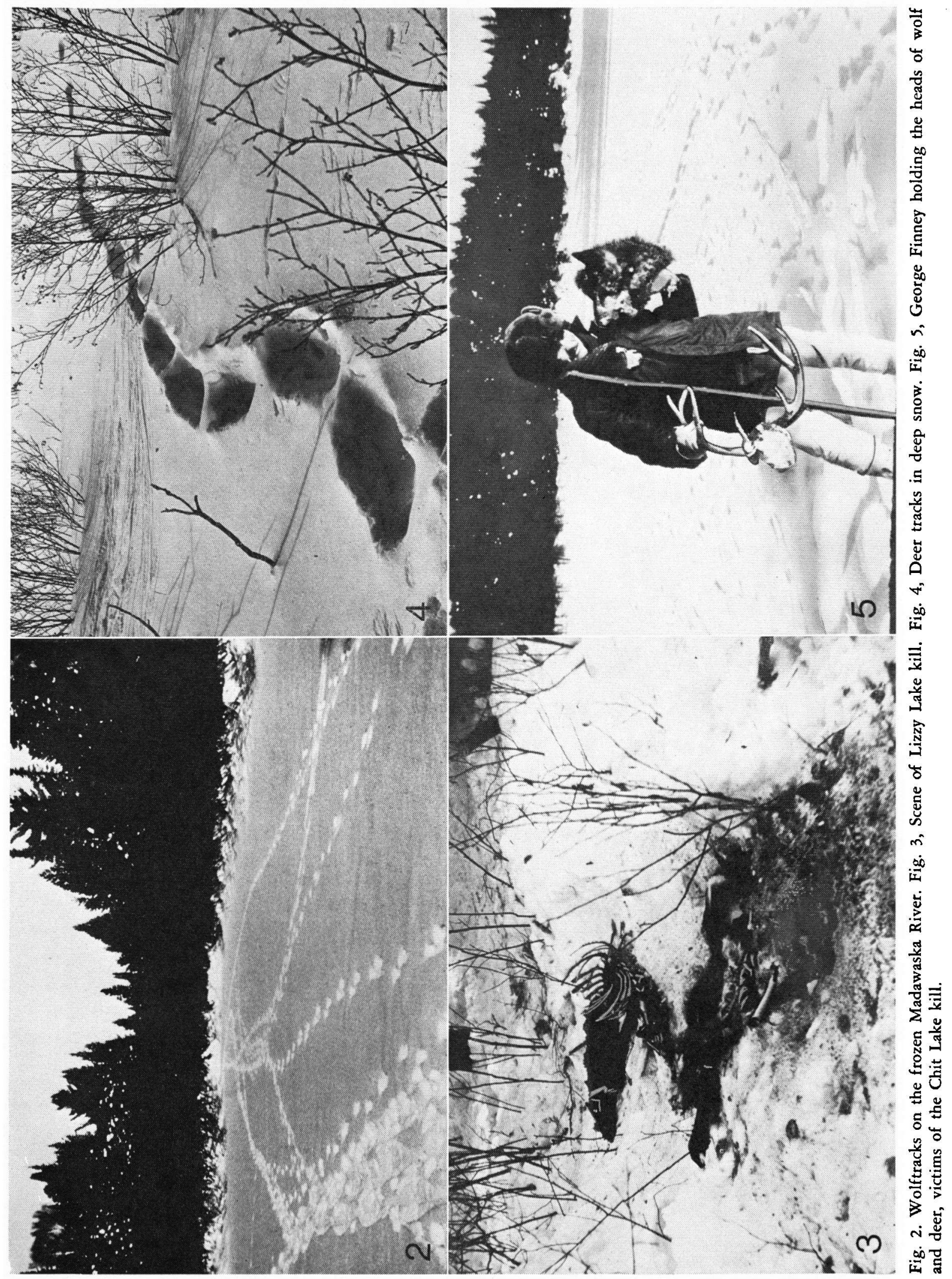




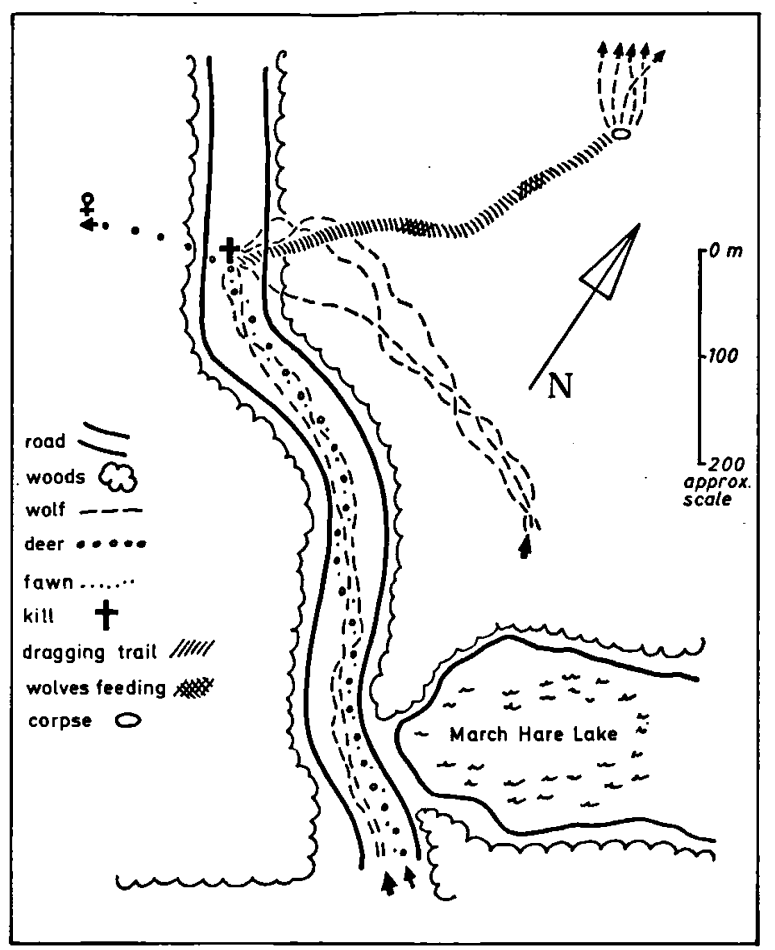

Fig. 6. Arowhon Taylor Statten Road kill.

presumably because of our approach. We were on the scene within half an hour of the moment the kill was actually made, as we concluded from the absence in the tracks of the light snow which had stopped falling only half an hour before. In the course of dragging off their prey, the wolves stopped three times in order to eat. On the last spot they must have fled in generally northerly directions when we came near. Apart from the head, the legs and the skin of the back, the fawn was then already completely eaten. Ravens had at that time already started eating from the blood-stained snow and other left-overs. The next day we found prints of many red foxes - at least 3 to $4-$ in the area of the kill. Foxes do clean up work on left-overs from wolf kills, especially in wintertime.

b) Madawaska River kill (nr. 2 in fig. 1, fig. 7)

Found on Febr. 2, 1969; kill (doe of over 5 yrs) made by Fool's pack, consisting of an estimated number of 7 or more wolves.

Two wolves (fig. 7, nrs 1 and 2) were walking on the frozen Madawaska River, one after the other. Then a deer crossed the river with great leaps, pursued by wolf nr. 3 . Wolf nr. 1 gave chase, flanking the deer back on the river. Wolf nr. 3 veered off his course and made for the place where the deer was to reappear. Also nr. 2 went directly to that spot and so did a 4th wolf, who appeared from the forest. If all the wolves were on the scene at the right time, the deer was caught between four wolves. The deer was killed - by how many of the wolves involved could not be read from the tracks - and almost completely eaten. Then the wolves left, travelling up river. In subsequent days the wintertime scavengers (ravens, foxes, jays and even titmice)

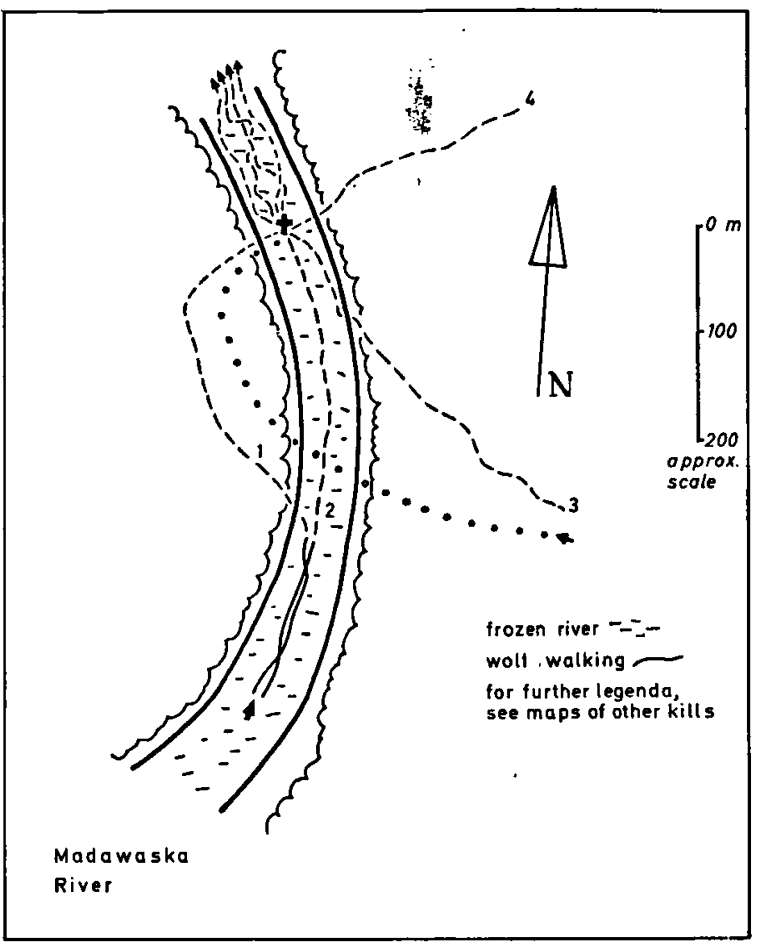

Fig. 7. Madawaska River kill.

of the Park cleaned up whatever was left, till after a fortnight only the bare skeleton remained.

c) Lizzy Lake kill (nr. 3 in fig. 1, fig. 8)

Found on Febr. 18, 1969, kill (buck, almost 3 yrs) made by Madawaska pack, consisting of an estimated number of 8 wolves.

This kill was found on a slope between the trees (Lizzy Lake lies in the hills south of the Lake of Two Rivers at a considerably higher level). The deer, an apparently healthy animal judging from bone marrow and stomach contents and in the prime of life, had followed the shore of Lizzy Lake and was then chased downhill by part of the pack ( 3 to 4 wolves). Another part (we counted the tracks of 3 wolves) had been following the creek, that drains Lizzy Lake into the Lake of Two Rivers. The two groups had separated when they left Lizzy Lake, but were probably never out of hearing distance. Halfway downhill the deer was brought down and killed after what must have been an unusually fierce fight: debris was scattered over a wide area, young trees broken off, etc. (fig. 3). Whether the deer was killed by either one of the groups of the split-up pack or caught between the two groups when they met on the hill slope could not be seen from the tracks. Snow conditions at the time were such, that the deer went in deeper than the wolves, which put the deer at a disadvantage.

d) Madawaska Swamp kill (nr. 4 in fig. 1, fig. 9)

Found on March 15, 1970; kill (doe, almost 2 yrs) made by 2-3 wolves, presumably from the Fool's pack.

$A$ deer had been resting in deep snow, facing away from the frozen, snowcovered swamp. Two or three wolves came 


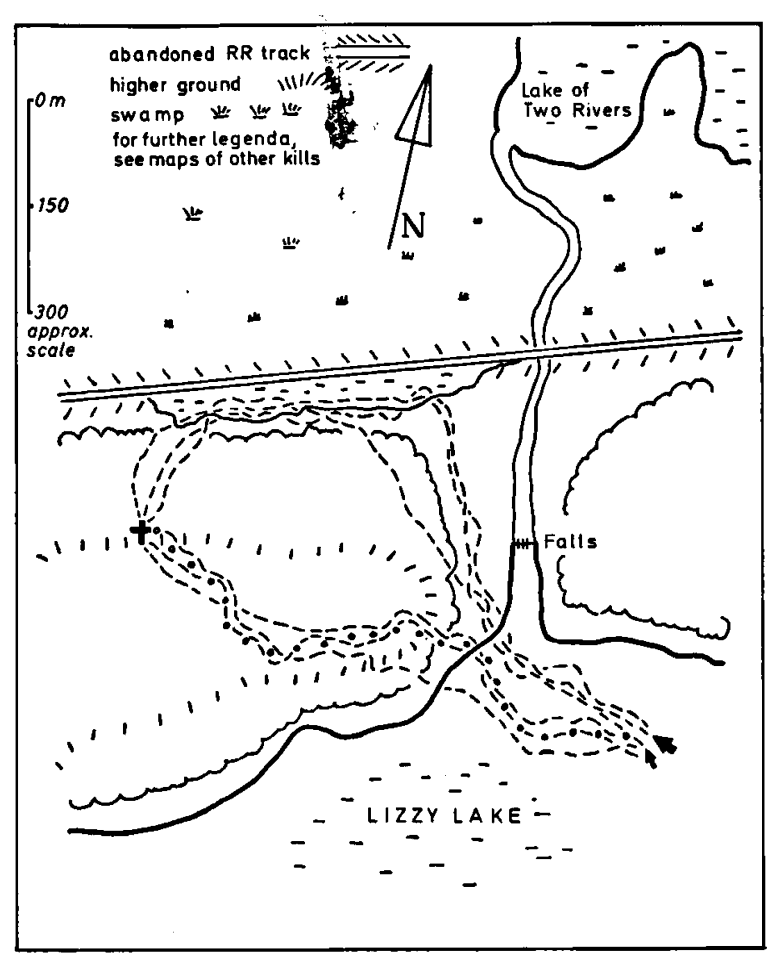

Fig. 8. Lizzy Lake kill.

in an easy lope down the trail towards the swamp. The deer started and jumped to its feet, running at first in the wolves' direction. Then it turned and fled towards the swamp. Snow conditions were such that the deer went in to half way its body at each jump, so leaving a chain of bathtub-like impressions (fig. 4), because the slight crust on the snow could not carry its weight. However, it was just strong enough to carry the wolves, who could travel lightly on top. Within 15 meters the wolves overtook their quarry and killed it. During the fight the deer emptied its bowels and bladder on several occasions. The prey was almost completely eaten, as indicated by the scattering of the legs (fig. 9).

e) Highway 60 kill (nr. 5 in fig. 1, fig. 10)

Found on Jan. 30, 1970; kill (female fawn) made by part (4-5 wolves) of the Madawaska pack.

A deer was chased over several hundreds of meters in a more or less straight line through the forest by part of the Madawaska pack. Then the deer hit upon Highway 60 , just north of the Lake of Two Rivers. At this spot blasting during the highway construction had resulted in a steep cliff of some 2-3 $\mathrm{m}$ height. The deer went over the cliff and may have hurt itself. Two wolves jumped after it, the others went around the cliff towards the deer. The deer was killed almost on the spot where it came down and subsequently dragged onto the road shoulder. At that time the wolves were presumably driven off by cars passing by at night. A motorist left a message with the Park authorities about seeing wolves crossing the road to the Lake of Two Rivers. The next morning we investigated the site and found the kill. The prey was not eaten but in such cases wolves usually come back in order to feed.

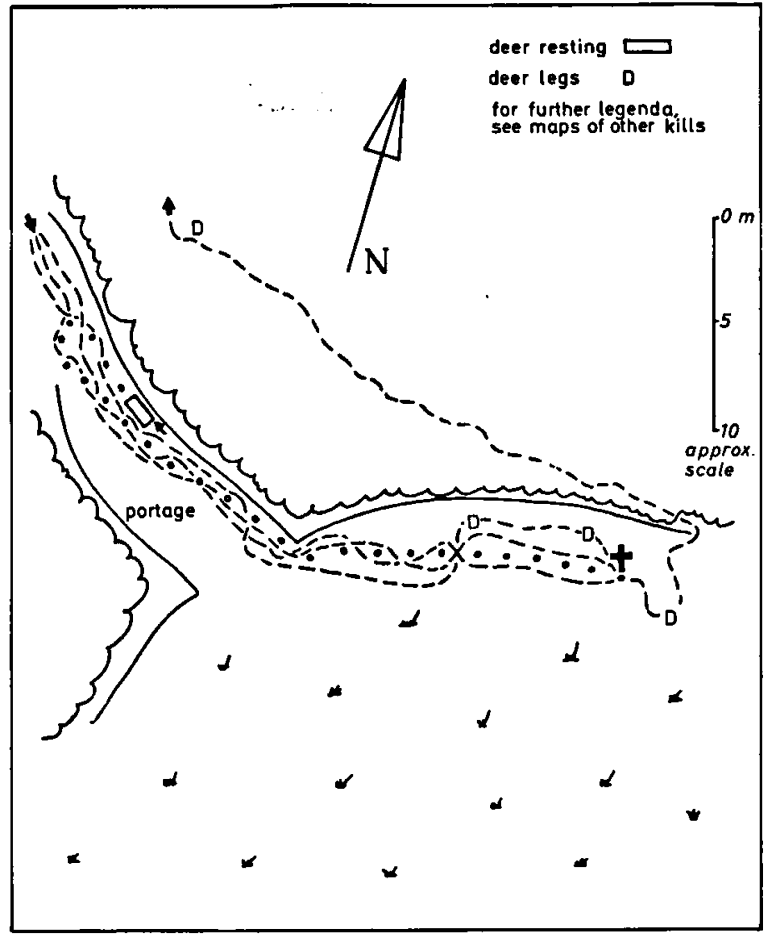

Fig. 9. Madawaska Swamp kill.

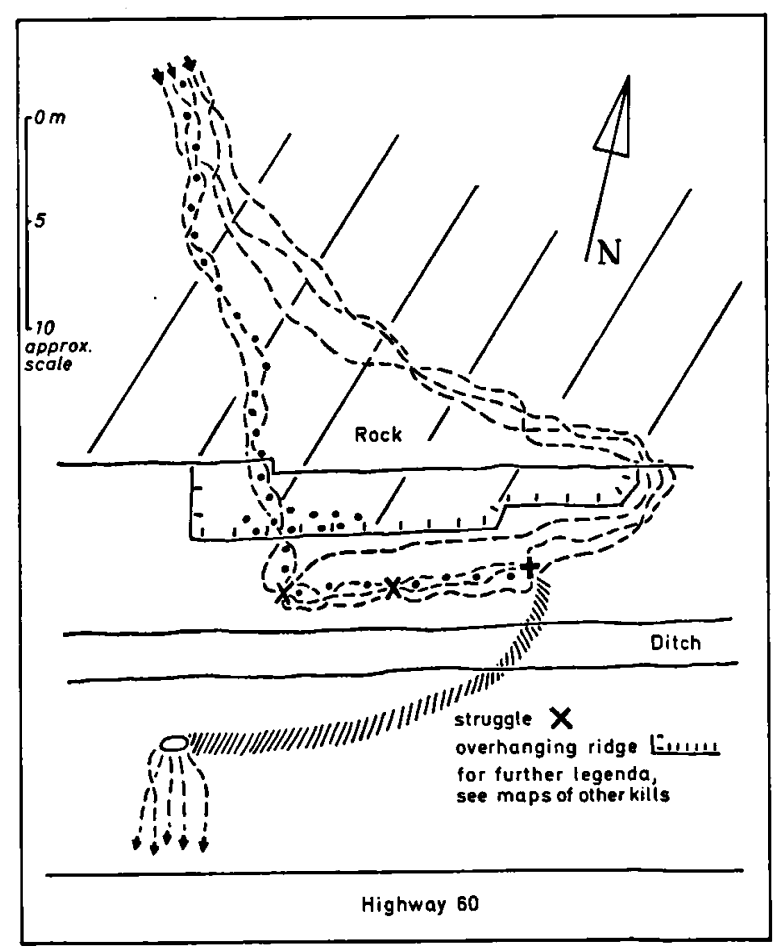

Fig. 10. Highway kill. 


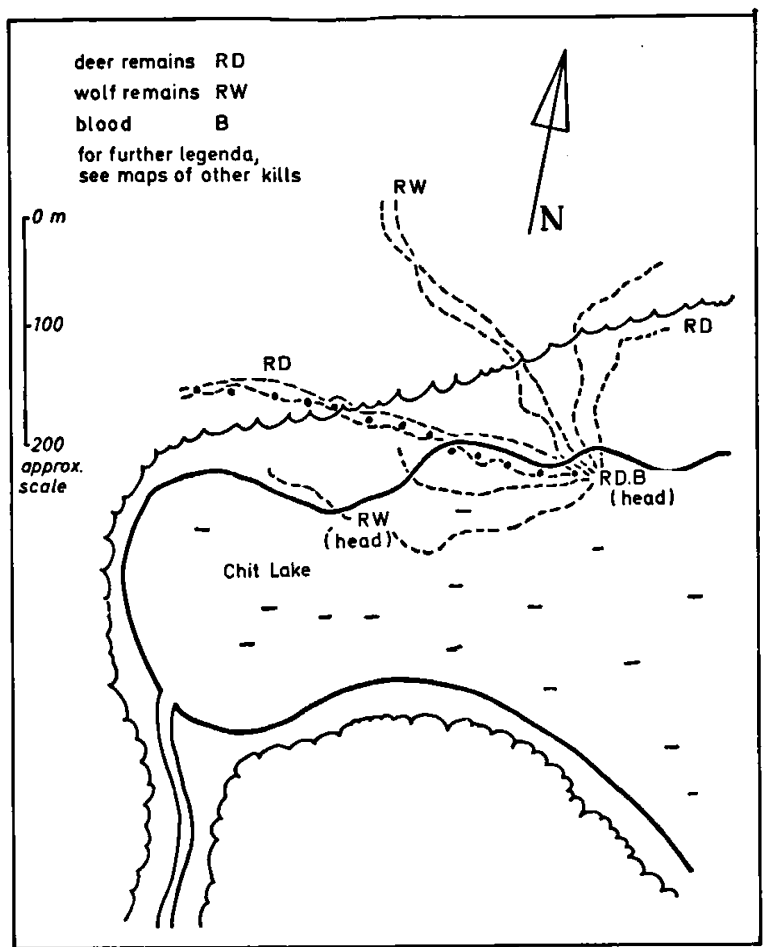

Fig. 11. Chit Lake kill.

f) Chit Lake kill (nr. 6 in fig. 1, fig. 11)

Found on Jan. 2, 1970; kill (buck, approx. 4 yrs) made by presumably combined Source and Fool's packs, 12 or more wolves.

Since the whole area was virtually littered with tracks, all that could be made out is, that a deer was driven out on Chit Lake and somehow brought to bay by the wolves. In the area we found not only the remainder of a white-tailed deer buck, but also the head of a wolf (fig. 5) and in nearby resting sites the gnawed off backbone, the legs and the tail of the wolf. Autopsy of the wolf's head indicated that the wolf had been severely wounded - probably even killed by a kick of the deer in its face. The lower left canine tooth was broken, the left cheek was slit open and part of the facial bones crushed. Examination of the brain by the Canada Department of Agriculture, Health of Animals Branch, revealed that the animal was suffering from rabies. This seems to provide an explanation for the wolf not being able to avoid the kicks of the deer hoofs. Although the diseased wolf was eaten by the rest of the pack(s) involved, no further cases of rabies have been reported from the area within the following six months.

\section{DISCUSSION}

The material presented does not allow to draw firm conclusions, although some of the phenomena observed are suggestive. Especially in combination with compilations of wolf hunting techniques, like Mech's (1970), one could speculate about a general underlying pattern (Frijlink, 1976). There are, however, some pertinent facts, that warrant discussion.

The $t r a v e l l i n g$ behaviour of a wolf pack, their constant fanning out and coming together again, greatly enhances their chances to hit upon a possible prey and eventually to close in on the prey from many or even all sides. On the one hand this behaviour may have given rise to the interpretation that wolves are intentionally patrolling or flushing certain areas (Banfield, as quoted by Mech, 1970: 198), on the other hand, one may wonder "whether or not a pack uses any strategy, beyond mere numbers" (Rutter \& Pimlott, 1968: 114).

I agree, that many stories about ambushing or other tactics supposedly applied by wolves, could be based upon this fanning behaviour or upon hot pursuit. But it is very well possible, perhaps even feasible, that, although certain tactics originate from hunting in a pack or from hot pursuit, evolution has made them part of the standard behaviour repertoire of the wolf through countless generations of natural selection. In no case, however, did we find any proof of ambushes. A case like the Arowhon Taylor Statten Road kill may represent how ambushing could possibly evolve from the earlier described spreading out behaviour but it is not an ambush itself, since the wolves involved, who emerged from the forest cover, at no place had been lying down but were, on the contrary, running at full speed.

Even in our modest figures a preference for making a kill out in the open was evident, the Lizzy Lake kill being the only exception. This could be a consequence of differences in agility between predator and prey, it is, however, also possible, that wolves attempt to drive their prey out in the open (e.g. the Madawaska River kill). Our material does not allow for a conclusive answer.

Wolves seem to be capable of taking advantage, when a sudden opportunity turns up. Especially the Madawaska Swamp kill and the Highway kill provide illustration for that. There is no reason, however, to surmise in the latter case, that the wolves intentionally chased the deer over the cliff, since the hunt went in a more or less straight line and the wolves could not possibly have influenced 
the deer's course. The more logical explanation is, that the deer came to the road on an unfortunate spot. Perhaps - being very young - it was not enough familiar with terrain conditions.

Finally the sixth case, the Chit Lake kill, presented us with some unusual phenomena. We assume, that two neighbouring packs, the Source and Fool's packs, had joined forces temporarily. In both winters of our study we noticed the temporary absence of wolf tracks in the Source Lake area, coinciding with the absence of deer. At the same time the number of wolves, estimated from counting tracks, in the Fool's pack jumped from about 9 to $12-15$ animals. Verne Oke, the local Park Resident, expressed his opinion, that such a combination was by no means unusual, and had occurred for many years already. According to him in the vicinity of Source Lake no good winter shelter was available for the deer, and when they moved out to winter yards (especially stands of hemlock trees, Tsuga canadensis) the wolves followed suit.

This case too, provided us with an example of a wolf, severely wounded or killed by its prey. We believe, that the wolf being diseased with rabies was an important factor in this event. Thirdly, we observed cannibalism in this case, apparently without serious consequences, since no wolves seemed to have contacted the disease in the ensuing months.

\section{ACKNOWLEDGEMENTS}

The University of Amsterdam and Queen's University, King. ston-Ont., enabled me to conduct field work in Canada. With gratitude I acknowledge the help I got from the Ontario Department of Lands and Forests and the staff of Algonquin Provincial Park. Financial support was given by the Netherlands Organization for Pure Scientific Research "Z.W.O." and Queen's University.

But most of all I owe to the enthousiastic help of many of my Canadian students, especially Liz Maskell, George Finney, Paul Mirsky, Don Snedden and Andy Langford.

\section{REFERENCES}

CrIsLer, L., 1956. Observations of wolves hunting caribou. J. Mammal., 37 (3): 337-346.

FriJliNk, J. H., 1976. In het spoor van de wolf: 1-209. (Strengholt, Naarden). (English edition "The way of the wolf", in prep.).

LAmbert, R. S. \& P. Pross, 1967. Renewing nature's wealth: i-xviii, 1-630. (Ont. Dept. Lands Forests).

MECH, L. D., 1966. The wolves of Isle Royale. Fauna of the National Parks of the United States. Fauna Series, 7: i-xiv, 1-210.

— 1970. The wolf: i-xxii, 1-385. (Nat. Hist. Press, New
York).

Murie, A., 1944. The wolves of Mount McKinley. Fauna of the National Parks of the United States. Fauna Series, 5: i-xx, 1-238.

Pimlott, D. H., J. A. Shannon \& G. B. Kolenosky, 1969. The ecology of the timber wolf in Algonquin Provincial Park. Ont. Dept. Lands Forests Res. Rep. (Wildlife), 87: 1-92, map.

Rutter, R. J. \& D. H. Pimlott, 1968. The world of the wolf: 1-202. (Lippincott Cy, Philadelphia \& New York). 